\title{
Global Warming was not Proved at Showa Base in Antarctica
}

\author{
Nobuyuki Miyatake $^{1}$, Noriko Sakano ${ }^{1}$, Shoko Murakami ${ }^{1}$, Takeshi Suzue ${ }^{2}$, Tomohiro Hirao ${ }^{2}$ \\ ${ }^{1}$ Department of Hygiene, Faculty of Medicine, Kagawa University, Miki, Kagawa, Japan; ${ }^{2}$ Department of Public Health, Faculty of \\ Medicine, Kagawa University, Miki, Kagawa, Japan. \\ Email: miyarin@med.kagawa-u.ac.jp
}

Received January 23 ${ }^{\text {rd }}, 2011$; revised March $6^{\text {th }}, 2011$; accepted April $18^{\text {th }}, 2011$.

\begin{abstract}
The changes in temperatures at Showa base in Antarctica were evaluated. Various parameters of temperatures at Showa base in Antarctica were obtained from Japan Metrological Agency. Parameters of temperatures were not correlated with years at Showa base (mean temperature in a year: $r=0.056, p=0.7267$ ). In addition, the number of days over $4^{\circ} \mathrm{C}$ was negatively correlated with years. Global warming was not proved at Showa base in Antarctica in this study.
\end{abstract}

Keywords: Temperature, Showa Base, Antarctica, Global Warming

\section{Introduction}

The world is a very different place today than it was only a short period ago. Also in Japan, urbanization and industrialization are accelerated. Global average temperatures are projected to increase by the end of this century. An increase in mortality related to heat waves has been reported from various industrialized countries [1-3]. For example, we have previously showed that estimated changes in mean temperature was $1.8^{\circ} \mathrm{C}$ for 50 years in Takamatsu areas, Japan [4]. In addition, by using monthly data, higher temperature was associated with ambulance transports in Takamatsu [5] and Okayama [6] areas, Japan. However, we could not found positive change in temperatures in Hachijo Inland, Japan [7], and whether an increase in temperatures is actually increasing in the world remains to be investigated. Therefore, the chronological changes in temperatures at Showa base in Antarctica were explored.

\section{Methods}

Daily temperatures at Showa base $\left(69^{\circ} 00^{\prime} \mathrm{S} 39^{\circ} 35^{\prime} \mathrm{E}\right)$ in Antarctica (1969-2009) were obtained from Japan Meteorological Agency [8]. Mean temperature, mean of the highest temperatures and mean of the lowest temperatures in January, August and a year were used for analysis. In addition, the changes in the number of days over various temperatures in January and those under various temperatures in August were also evaluated.

Simple correlation analysis was used to test the significance of the linear relationship among continuous variables: $p<0.05$ was considered to be statistically significant. Statistical analysis was performed with StatView 5.0 (SAS Institute Inc., Cary, NC, USA).

\section{Results}

Mean temperature, mean of the highest temperatures and mean of the lowest temperatures in January, August and a year at Showa base were not significantly correlated with years (mean temperature in a year: $r=0.056, p=$ 0.7267) (Table 1, Figure 1). In addition, we evaluated the relationship between years and various levels of temperatures in January and August at Showa base (Table 2). The number of days of over 3,4 and $5^{\circ} \mathrm{C}$ in January was negatively correlated with years (Figure 2). Coefficient rate between years and over $4^{\circ} \mathrm{C}$ was the highest in January. However, the number of days under $-25^{\circ} \mathrm{C}$ was not correlated with years in August $(r=-0.205, p=$ 0.1984).

\section{Discussion}

Although we previously found positive changes in temperatures in Takamatsu and Okayama areas, Japan, clinical impact of global warming effect at Showa base in Antarctica was not noted in this study. 
Table 1. Relationship between parameters of temperature and years at Showa base.

\begin{tabular}{cccccccc}
\hline & \multicolumn{2}{c}{ January } & \multicolumn{3}{c}{ August } & \multicolumn{2}{c}{ Total } \\
\hline & $r$ & $p$ & $r$ & $p$ & $r$ & 0.056 \\
\hline Mean Temperature & -0.191 & 0.2328 & 0.206 & 0.1961 & 0.7267 \\
Mean of the Highest Temperature & -0.303 & 0.0546 & 0.217 & 0.1727 & -0.005 & 0.9743 \\
Mean of the Lowest Temperature & -0.097 & 0.5473 & 0.226 & 0.1551 & 0.088 & 0.5847 \\
\hline
\end{tabular}

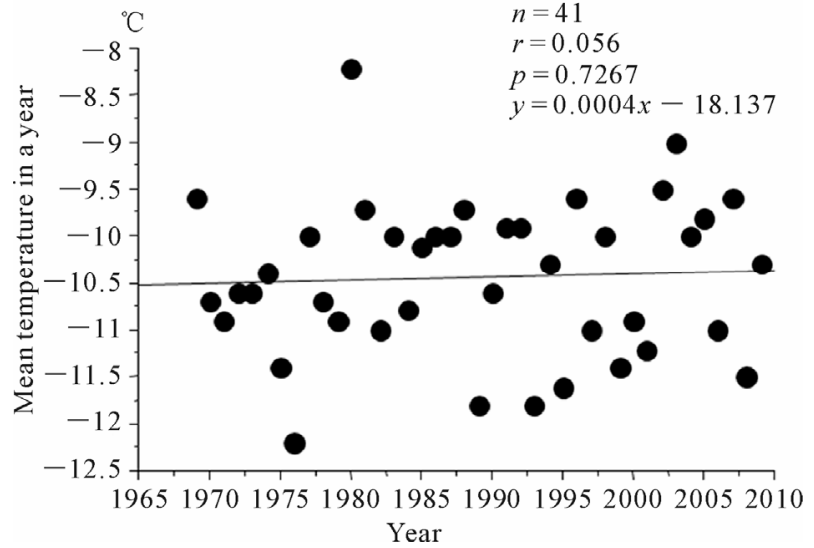

Figure 1. Simple correlation analysis between mean temperature in a year and years at Showa base in Antarctica (1969 2009).

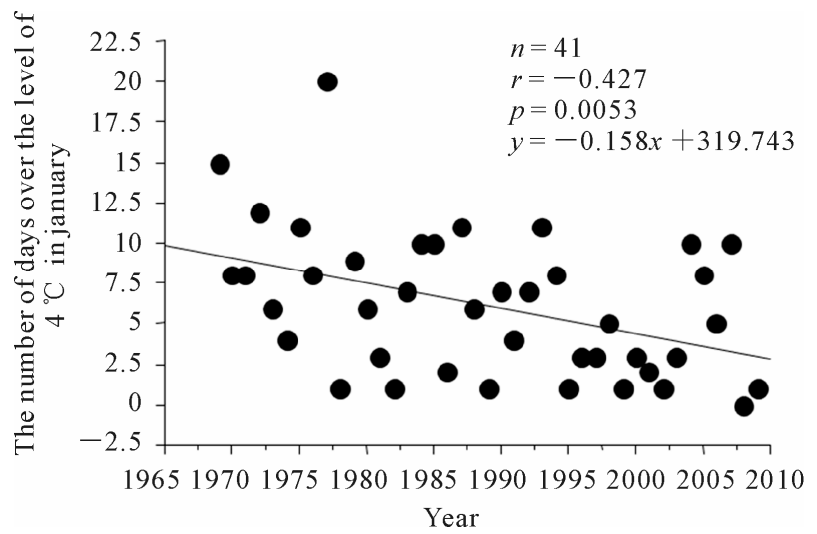

Figure 2. Simple correlation analysis between the number of days over $4^{\circ} \mathrm{C}$ in January and years at Showa base in Antarctica (1969 2009).

Table 2 Relationship between years and various levels of temperature in Janualy and August at Showa base in Antarctica.

\begin{tabular}{cccccc}
\hline \multicolumn{3}{c}{ January } & & \multicolumn{2}{c}{ August } \\
\hline & $r$ & $p$ & & $r$ & $p$ \\
\hline $0^{\circ} \mathrm{C} \leqq$ & -0.030 & 0.8503 & $\leqq-25^{\circ} \mathrm{C}$ & -0.205 & 0.1984 \\
$1^{\circ} \mathrm{C} \leqq$ & -0.144 & 0.3681 & $\leqq-26^{\circ} \mathrm{C}$ & -0.237 & 0.1356 \\
$2^{\circ} \mathrm{C} \leqq$ & -0.272 & 0.0858 & $\leqq-27^{\circ} \mathrm{C}$ & -0.207 & 0.1936 \\
$3^{\circ} \mathrm{C} \leqq$ & -0.348 & $\mathbf{0 . 0 2 5 8}$ & $\leqq-28^{\circ} \mathrm{C}$ & -0.165 & 0.3039 \\
$4^{\circ} \mathrm{C} \leqq$ & -0.427 & $\mathbf{0 . 0 0 5 3}$ & $\leqq-29^{\circ} \mathrm{C}$ & -0.120 & 0.4563 \\
$5^{\circ} \mathrm{C} \leqq$ & -0.407 & $\mathbf{0 . 0 0 8 3}$ & $\leqq-30^{\circ} \mathrm{C}$ & -0.156 & 0.3299 \\
\hline
\end{tabular}

Average subsurface temperature profiles in four Asian cities (Tokyo, Osaka, Seoul and Bangkok) were compared and analyzed to evaluate the effects of surface warming [9]. The magnitude of surface warming was the largest in Tokyo $\left(2.8^{\circ} \mathrm{C}\right)$, followed by Seoul, Osaka and Bangkok. Nakai et al investigated heat-related deaths in Japan from 1968 through 1994 and heat-related deaths were most prone to occur on days with a peak daily temperature above $38^{\circ} \mathrm{C}$ [10]. In addition, they reported that incidence of heat-related deaths showed and exponential dependence on the number of hot days [10]. Bai et al. also showed that the number of unusual deaths in the summer of 1994 in Osaka, Japan was more compared to those of previous years [11]. Qui et al. reported that an unusually hot spell in 1999 was followed by a high mortality rate in Hokkaido, Japan [12]. When the air temperature is over $34^{\circ} \mathrm{C}$, cardiovascular and nervous disorders can occur as a result of problems associated with body temperature adjustment and metabolism of water and salts [12]. Unexpectedly high temperatures are particularly difficult for chronic diseases [13] and the elderly [14,15].

However, mean temperature in a year was not correlated with years in this study. In addition, the number of days of over $4^{\circ} \mathrm{C}$ in January was negatively correlated with years. Although the mechanism was not proved in this study, the evidence of global warming was not proved at Showa base in Antarctica. Further observation was urgently required to prove the global warming.

\section{REFERENCES}

[1] M. Lye and A. Kamal, "Effects of a Heatwave on Mortality-Rates in Elderly Inpatients,” Lancet, Vol. 1, No. 8010, March 1977, pp. 529-531. doi:10.1016/S0140-6736(77)91385-X

[2] K. E. Smoyer, "A Comparative Analysis of Heat Waves and Associated Mortality in St. Louis, Missouri-1980 and 1995,” International Journal of Biometeorology, Vol. 42, No. 1, September 1998, pp. 44-50. doi:10.1007/s004840050082

[3] W. B. Applegate, J. W. Jr. Runyan, L. Brasfield, M. L. Williams, C. Konigsberg and C. Fouche," Analysis of the 1980 Heat Wave in Memphis," Journal of the American Geriatrics Society, Vol. 29, No. 8, August 1981, pp. 337-342.

[4] N. Miyatake, N. Sakano, S. Murakami, S. Suna, T. Suzue 
and T. Hirao, "Comparison of the Temperatures among Rural, Urban and Metropolitan Areas around the Inland Sea in Japan,” Environmental Monitoring and Assessment, Springer, Berlin, 2011, in press.

[5] N. Miyatake, M. Nakao, N. Sakano, S. Suna, T. Suzue and T. Hirao, "Higher Ambulance Transports were Closely Associated with Higher Ambulance Transports in Takamatsu Area, Japan,” Journal of Environmental Protection, Vol. 2, No. 1, March 2011, pp.72-75.

[6] N. Sakano, M. Miyatake, T. Suzue, S. Suna, T. Hirao and K. Ogino, "The Relation between High Temperatures and Ambulance Transports in Okayama City, Japan,” Journal of Preventive Medicine, in Japanese, Vol. 6, No. 1, March 2011. pp. 17-20.

[7] N. Sakano, M. Miyatake, S. Murakami, T. Suzue, T. Hirao and K. Ogino, "Changes in Temperatures in Okayama Area Compared with Different Urbanization Areas, Japan,” Journal of Environmental Protection, Vol. 2, No. 2, April 2011, pp. 162-167.

[8] Japan Meteorological Agency, 2010. Internet Available: http://www.data.jma.go.jp/obd/stats/etrn/index.php?prec_ no=99\&prec_ch=\%93\%EC\%8B\%C9\&block_no=89532 \&block_ch=\%8F\%BA\%98a\&year $=\&$ month $=\&$ day $=$ \&vie $\mathrm{w}=$

[9] M. Taniguchi, T. Uemura and K. Jagoon, "Combined Effects of Urbanization and Global Warming on Subsurface Temperature in for Asian Cities," Vadose Zone Journal, Vol. 6, No. 3, August 2007, pp. 591-596. doi:10.2136/vzj2006.0094

[10] S. Nakai, T. Itoh and T. Morimoto, "Deaths from Heat-
Stroke in Japan: 1968-1994,” International Journal of Biometeorology, Vol. 43, No. 3, November 1999, pp. 124-127. doi:10.1007/s004840050127

[11] H. Bai, M. N. Islam, H. Kuroki, K. Honda and C. Wakasugi, "Deaths Due to Heat Waves during the Summer of 1994 in Osaka Prefecture, Japan,” Nihon Hoigaku Zasshi, in Japanese, Vol. 49, No. 4, August 1995, pp. 265-274.

[12] D. Qiu, T. Tanihata, H. Aoyama, T. Fujita, Y. Inaba and M. Minowa, "Relationship between a High Mortality Rate and Extreme Heat during the Summer of 1999 in Hokkaido Prefecture, Japan,” Journal of Epidemiology, Vol. 12, No. 3, May 2002, pp. 254-257.

[13] J. C. Semenza, C. H. Rubin, K. H. Falter, J. D. Selanikio, W. D. Flanders, H. L. Howe and J. L. Wilhelm, "HeatRelated Deaths during the July 1995 Heat Wave in Chicago,” New England Journal of Medicine, Vol. 335, No. 2, July 1996, pp. 84-90. doi:10.1056/NEJM199607113350203

[14] J. B. Worfolk, "Heat Waves: Their Impact on the Health of Elders," Geriatric Nursing, Vol. 21, No. 2, MarchApril 2000, pp. 70-77. doi:10.1067/mgn.2000.107131

[15] T. S. Jones, A. P. Liang, E. M. Kibourrne, M. R. Griffin, P. A. Patriarca, S. G. Wassilak, R. J. Mullan, R. F. Herrick, H. D. Jr. Donnell, K. Choi and S. B. Thancker, "Morbidity and Mortality Associated with the July 1980 Heat Wave in St. Louis and Kansas City, Mo,” The Journal of the American Medical Association, Vol. 247, No. 24, June 1982, pp. 3327-3331. doi:10.1001/jama.247.24.3327 